\title{
Development of materials and technologies for control of polymer recycling
}

\author{
Haruo Nishida
}

The movement toward a recycling-based society through the essential development of recyclable materials alongside technologies for controlling recycling is reviewed. Recently, there has been progress in producing various polymers and technologies with the aim of achieving circulative utilization. For example, the upgrade recycling of commodity plastics, selective transformation of engineering plastics, selective depolymerization of various polymers in supercritical fluids, crosslinking-decrosslinking control using reversible reactions and developments in biomass-based recyclable polymers. Despite great strides taken in the effectiveness, efficiency and precision of these polymers and technologies, further improvements will be required to meet the practical requirements of a responsible sustainable system for the recycling of containers, packages, electric household appliances and end-of-life vehicles all of which are operated in compliance with the recycling laws of Japan. Polymer Journal (2011) 43, 435-447; doi:10.1038/pj.2011.16; published online 16 March 2011

Keywords: biomass-based recyclable polymers; circulative utilization; crosslinking-decrosslinking; polymer recycling; selective depolymerization; selective transformation; supercritical fluids

\section{INTRODUCTION}

In Japan, 'The Basic Law for Establishing the Recycling-based Society' was enacted in May 2000 with the aim of driving Japan toward a recycling-based society appropriate to the twenty-first century. The legislation sets out concrete proposals with the introduction of action plans for (1) reduction through restrictions in the generation of waste (2) reuse of materials (3) recycling and (4) appropriate disposal of waste. Additional specific pieces of legislation relating to the recycling of container and packaging, electrical household appliances, construction material, food and end-of-life vehicles, have also been enacted. Thus, Japan has embarked on a social experiment, which will ultimately require the circulative utilization of the majority of its resources.

Nowadays, in the movement toward achieving zero-discharge and sustainability, already commonplace terms such as 'carbon neutral', 'renewal resources' and 'circulative utilization' are being joined by other keywords from the field of polymer chemistry, such as 'recycling, 'reversible', 're-workable', 'decrosslinking' and 'biomass-based', all of which are indicative of a gradual but steadily progressing paradigm-shift toward sustainable technology. In fact to carry out the remit of the basic law, all plastics will ultimately be required to be recycled. As regards recyclability, most commodity plastics are relatively stable making monomer recovery poor. There are, however, some plastics, the so-called: 'recyclable plastics', possessing the important and superior attribute of being able to be converted into valuable raw chemicals. One special category of plastics, termed 'depolymerizable plastics' is capable of being returned to the corresponding monomers. For example, poly(methyl methacrylate) (PMMA), polyethylene terephthalate (PET), nylon-6 and poly(lactic acid) (PLA) are well-known examples of depolymerizable plastics. Recently, the movement and developments of polymer recycling technologies in Japan have been summarized in a book. ${ }^{1}$

This review highlights the progress made in materials and technologies for the recycling of polymeric materials, that is, feedstock recycling of commodity and engineering plastics, recycling technology using super/subcritical fluids, control of crosslinking-decrosslinking and development of biomass-originated polymers.

\section{DEVELOPMENT IN FEEDSTOCK RECYCLING OF COMMODITY PLASTICS}

Effect of temperature on monomer recovery

Polyethylene (PE) and polypropylene (PP) as typical commodity plastics are better known as randomly degrading polymers rather than depolymerizing polymers. ${ }^{2}$ This is not surprising because the heat of polymerization, an important parameter for estimating the depolymerizability of polymers, has larger negative values for ethylene and propylene, than for styrene (St) and methyl methacrylate, indicating the difficulty in depolymerizing $\mathrm{PE}$ and $\mathrm{PP} .^{3}$ However, cases in which the zip length is controlled by chain-transfer reactions and in which the activation energy value for a depolymerization reaction, such as $\beta$-scission, is higher than that of the chain-transfer reactions, the monomer yield can be increased with increase in 




Figure 1 Recovery of monomers and $\mathrm{C}_{2}-\mathrm{C}_{4}$ monoolefins from polyethylene (PE), polypropylene (PP) and polystyrene (PS) by pyrolysis.

temperature. In Figure 1, the recovery of monomer and $\mathrm{C}_{2}-\mathrm{C}_{4}$ monoolefin fractions from $\mathrm{PE}^{4-9}, \mathrm{PP}^{10-12}$ and polystyrene (PS) ${ }^{13-16}$ are illustrated. Ethylene and propylene recovery have been achieved at levels up to around $60 \%$ and St has been confirmed to be recovered at around $80 \%$. From the view point of $\mathrm{C}_{2}-\mathrm{C}_{4}$ monoolefin fractions recovery, very high values of more than $90 \%$ have been achieved for all the plastics.

To decrease coking during the pyrolysis of PE, a two-stage thermal gasification method has been reported by Tsuji et al. ${ }^{6}$ Zassa et al. ${ }^{4}$ also examined the two-stage pyrolysis process of linear low-density polyethylene: first a low-temperature $\left(<450^{\circ} \mathrm{C}\right)$ thermal pyrolysis and second thermal cracking $\left(>800^{\circ} \mathrm{C}\right.$, residence time $\left.<1.3 \mathrm{~s}\right)$. Their aim was to control the homogeneous gas phase reactions at high temperatures by decoupling them from the heterogeneous reactions in the first degradation steps. Splitting the process allowed independent control of the reaction time and circumvented the limitations of a multiphase reacting system. The result was a dramatic improvement in the ethylene yield to as much as $60 \%$, temporarily $75 \%$, of total gaseous product.

Sawaguchi et al. ${ }^{11}$ reported the highest propylene recovery $(48.6 \mathrm{wt} \%)$ from PP by pyrolysis in a temperature range of 500 $650{ }^{\circ} \mathrm{C}$. At the same time, they found a high recovery ratio $(85-$ $86 \mathrm{wt} \%)$ of $\mathrm{C}_{2}-\mathrm{C}_{4}$ monoolefins in the gaseous degradation products.

Westerhout et al. ${ }^{5,9,10}$ demonstrated the highest recovery of $\mathrm{C}_{2}-\mathrm{C}_{4}$ monoolefins from $\mathrm{PE}$ and $\mathrm{PP}$ waste using appropriate pyrolysis reactors and conditions. They operated a tubular reactor in a temperature range of $650-850{ }^{\circ} \mathrm{C}$ for a residence time of between 0.1 and $1 \mathrm{~s}$, resulting in the very efficient recovery of $\mathrm{C}_{2}-\mathrm{C}_{4}$ monoolefins as products with total values higher than $90 \%$. They also developed the rotating cone reactor with a fluidized sand bed for the pyrolysis of the plastic waste.

Monomer recovery from PS has been investigated for many years. Depending on experimental conditions, various oligomeric compounds such as dimer and trimer are formed as well as monomer St. ${ }^{17}$ Sawaguchi and Seno ${ }^{18}$ investigated simplified volatile products, mainly consisting of monomer, dimer and trimer in a low-temperature range of $310-350^{\circ} \mathrm{C}$ under vacuum. They found that the lower the degradation temperature, the larger the trimer formed up to $76.5 \mathrm{wt} \%$. As the degradation temperature was increased, the monomer content increased up to $64.4 \mathrm{wt} \%$. At $640{ }^{\circ} \mathrm{C}$, Sinn et al..$^{13}$ reported the highest recovery $(79.8 \mathrm{wt} \%)$ of St from PS pyrolysis using a test plant with a fluidized sand bed.

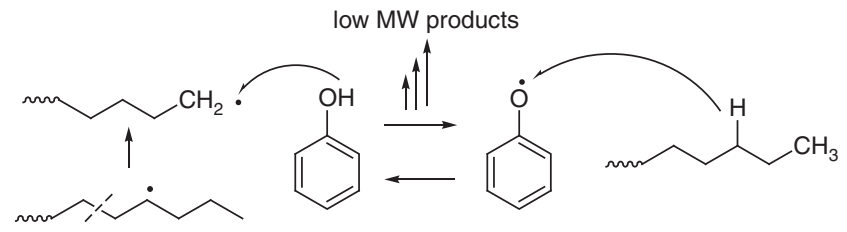

Scheme 1 High-density polyethylene thermal degradation in the presence of phenol.

\section{Effects of additives and catalysts}

The thermal cracking of high-density polyethylene was carried out in the presence of phenol at $400{ }^{\circ} \mathrm{C}$ to focus on the effect of the phenol/ plastic ratio on the yield and distribution of the pyrolytic products (Scheme 1). ${ }^{19}$ The presence of phenol enhanced the reaction such that a complete conversion into $\mathrm{C}_{1}-\mathrm{C}_{55}$ hydrocarbons was achieved. The yield of $\alpha$-olefins as main products increased with the amount of phenol, indicating that the phenol promotes the thermal degradation of high-density polyethylene. The proposed reaction mechanisms include random scissions and chain reactions, which are favored by the presence of phenol (Scheme 1).

Uemichi et al. ${ }^{20-22}$ have been investigating the catalytic degradation of $\mathrm{PE}$ and $\mathrm{PP}$ into benzene, toluene and xylenes, or $\mathrm{C}_{3}-\mathrm{C}_{5}$ monoolefins by using $\mathrm{H}$-gallosilicate or $\mathrm{H}$-borosilicate catalysts, respectively. Products benzene, toluene and xylenes or $\mathrm{C}_{3}-\mathrm{C}_{5}$ monoolefins were recovered in yields of 61.8 or $75.5 \mathrm{wt} \%$, respectively, at $525^{\circ} \mathrm{C}$. Moreover, the catalytic degradation of low-density polyethylene including poly(vinyl chloride) was also tried using a chlorine tolerant catalyst: $\mathrm{H}$-galloaluminosilicate, when it was found that the catalyst had a high activity for converting low-density polyethylene into aromatic hydrocarbons even in the presence of poly(vinyl chloride). ${ }^{23}$

Zhang et al. ${ }^{15}$ examined the catalytic degradation of waste PS into St using solid acids and bases, finding that solid bases were effective catalysts for the chemical recycling of PS. In particular, barium oxide gave oily products in a yield of $93.4 \%$ including St at $76.4 \%$.

\section{Upgrade recycling of commodity plastics}

Sawaguchi et al. ${ }^{24,25}$ has been reporting the selective synthesis of telechelic oligopropylene, having terminal vinylidene double bonds at both ends, by controlled thermal degradation of isotactic PP (iPP) (Scheme 2). The terminal vinylidene double bond groups were modified into various $\alpha, \omega$-bifunctional groups as shown in Scheme $2,{ }^{26}$ for example, $\alpha, \omega$-dibromoisobutyrate to allow them to function as bifunctional macroinitiators: $\mathrm{Br}-\mathrm{iPP}-\mathrm{Br}$. Triblock copolymers: PS-iPP-PS and PMMA-iPP-PMMA were obtained by atom transfer radical polymerization of St and methyl methacrylate, respectively, using $\mathrm{Br}-\mathrm{iPP}-\mathrm{Br}^{27}$ It was confirmed that the PMMA-iPP-PMMA triblock copolymer was an effective additive as a compatibilizer for the PP/PMMA blend.

Yoshida et al. ${ }^{28}$ degraded stereoregulated PP: iPP and syndiotactic PP under oxidative conditions using $\mathrm{NO}_{2}$ in supercritical $\mathrm{CO}_{2}$ to convert into various kinds of $\alpha, \omega$-dicarboxyl compounds, for example, syn-2,4-dimethyl glutaric acid and anti-2,4-dimethyl adipic acid (Scheme 3). The products retained the original stereoregularity of iPP and syndiotactic PP.

\section{Molecular design of degradable polyolefins}

To prepare degradable polyolefins, Shiono et al. ${ }^{29-31}$ designed polyolefin analogs containing internal ester linkages in main chains. They synthesized the analogs in various ways using combinations of (1) the partial hydrogenation of polybutadiene or the copolymerization of 


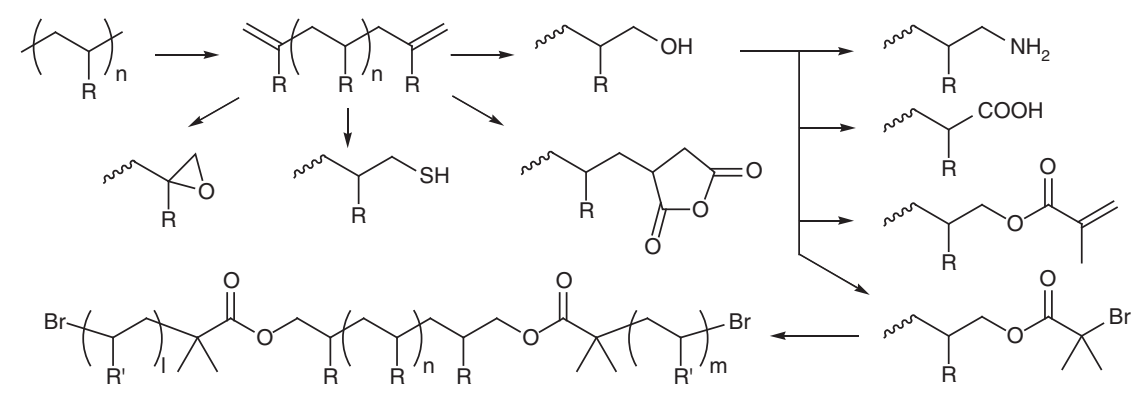

Scheme 2 Upgrade recycling of isotactic polypropylene to telechelic oligopropylene having terminal vinylidene double bonds.
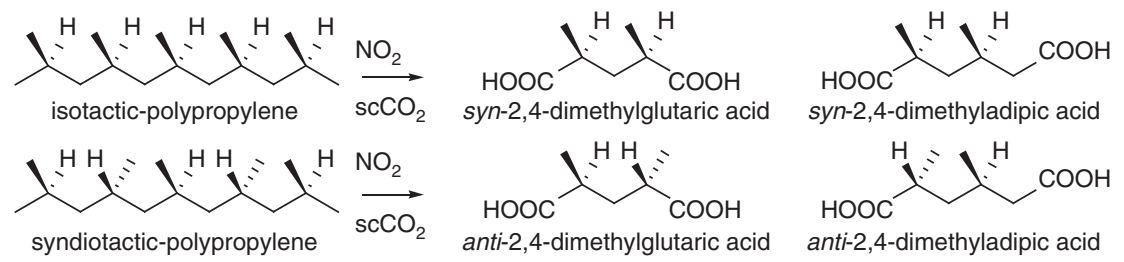

Scheme 3 Upgrade recycling of isotactic polypropylene and syndiotactic polypropylene into stereoregulated $\alpha, \omega$-dicarboxyl compounds.



Scheme 4 Mechanistic pathway for a metathetical reaction.

ethylene and propylene with butadiene to obtain poly(olefin-ran1,3-butadiene)s (I), (2) the metathesis degradation of $\mathbf{I}$ with ethylene to obtain $\alpha, \omega$-divinyl-polyolefins, (3) the oxidative degradation or hydroboration/oxidation of vinyl groups to obtain $\alpha, \omega$-dihydroxy or $\alpha, \omega$-dicarboxy-polyolefins, followed by (4) esterification with complementary dihydroxyl or dicarboxyl compounds to obtain the degradable polyolefin analogs. The average length of propylene units between butadiene units in I becomes longer according to the propylene concentration in the feed.

Lucas et al. ${ }^{32}$ synthesized dihydroxy-telechelic poly(ethylene-co-1, 3-butadiene) by metathetical depolymerization of high-molecular weight copolymers in the presence of the first generation Grubbs catalyst and cis-1,4-diacetoxy-2-butene as a functionalizing chain transfer agent, followed by hydrolysis of the acetoxy chain ends (Scheme 4). Although the formation of telechelic oligomers is complicated by a fast back-biting reaction leading to cyclohexene and macrocycles production, the cyclic products finally yielded linear dihydroxy telechelic oligomers when excess chain transfer agents were introduced to the cyclic products.

\section{EFFECTIVE AND SELECTIVE DEPOLYMERIZATION IN SUPERCRITICAL AND SUBCRITICAL FLUIDS}

\section{Synthetic networked polymers}

Sub- and supercritical fluids such as water and alcohol are excellent reaction media for the depolymerization or decomposition of plastics. ${ }^{33}$ By using sub- and supercritical fluids, the depolymerization of condensation polymerization polymers, such as PET, nylone- 6 and polyurethane (PU), proceeds relatively easily and selectively to their monomers, which are recovered with high yields. Recently, the treating of crosslinked polymers, so-called networked polymers, with sub- and supercritical fluids is being investigated to make the post-consumed products easier to treat.

Nakagawa et al. ${ }^{34}$ have developed a smart recycling technology for the fiber reinforced plastic (FRP) using subcritical water. With this technology, thermosetting resin in FRP can be recycled at a recycling rate of $70 \%$. Components of unsaturated polyester resin, such as glycols and fumaric acid, were separated from the aqueous reaction liquid to be reused for new unsaturated polyester preparation as raw materials. Reuse has also been made of recovered styrene-fumaric acid copolymer obtained in the aqueous phase, along with its inorganic components, for new FRP production as a low-profile additive and inorganic filler, respectively.

Suyama et al. ${ }^{35}$ decrosslinked unsaturated polyester in subcritical water in the presence of aminoalcohol, resulting in the recovery of linear PS derivatives bearing hydroxy-terminated side-chains (Scheme 5). After modification of the hydroxy groups with maleic anhydride, the PS derivatives were re-crosslinked with St to recreate a networked structure. The resulting networked polymer was also degradable by subcritical water treatment in the presence of aminoalcohol to give other PS derivatives bearing hydroxy groups in the side chains. This process is repeatable and has demonstrated its applicability as a novel recycling system for thermosetting resins.

Goto et al. ${ }^{36}$ reported that silane-crosslinked polyethylene, which is used as a cable insulation material, is recyclable as a thermoplastic PE by treatment with supercritical methanol (Scheme 6). The recycling process required treatment conditions of $270-320^{\circ} \mathrm{C}$ and $5-12 \mathrm{MPa}$, which, for the supercritical fluid treatment, were more efficiently achieved in an extruder rather than using conventional reactor methods, and resulted in less energy consumption than the production process for virgin PE.

Yoshida et al. ${ }^{37}$ investigated the plasticity recovery of a peroxidecrosslinked PE using the oxidation method in supercritical $\mathrm{CO}_{2}$. When nitrogen dioxide $\left(\mathrm{NO}_{2}\right)$ was used as an oxidant, the selective oxidation was conducted at $85^{\circ} \mathrm{C}$ and $19 \mathrm{MPa}$ for $18 \mathrm{~h}$ to give a product, which although having no gel fraction, had oxidized carboxyl groups at chain ends. When $\mathrm{H}_{2} \mathrm{O}_{2}$ oxidation was conducted at $120^{\circ} \mathrm{C}$ and $10 \mathrm{MPa}$ for 




Scheme 5 Chemical recycling of unsaturated polyester with sc-water.

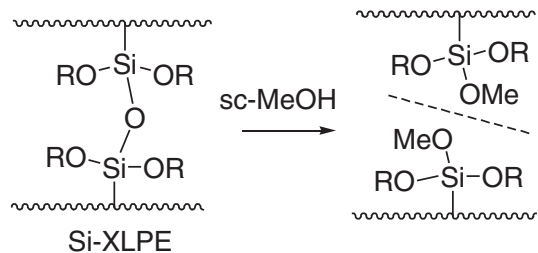

Scheme 6 Chemical recycling of silane-crosslinked polyethylene in supercritical methanol.

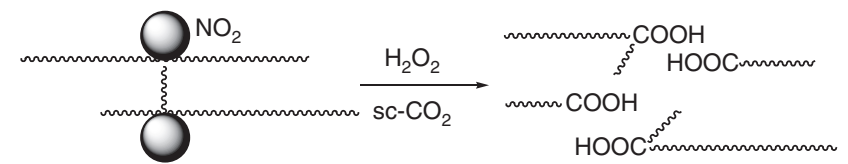

Scheme 7 Selective decrosslinking of crosslinked polyethylene with $\mathrm{H}_{2} \mathrm{O}_{2}$ in $\mathrm{Sc}-\mathrm{CO}_{2}$.

$3 \mathrm{~h}$, the product obtained had superior recovery of plasticity to that treated by $\mathrm{NO}_{2}$ (Scheme 7).

Matsumoto et al..$^{38}$ revealed that, when slightly degradable crosslinked polyureas were treated in supercritical $\mathrm{CO}_{2}$ with only small amount of water, amines as raw materials were recovered with no side reaction. The optimum hydrolysis conditions were at $190^{\circ} \mathrm{C}$ and 7.4 MPa.

\section{Selective hydrolysis of cellulose}

Cellulose, the most abundant biological polysaccharide, is possessed by all plants and algae. This plentiful and useful material has, after use, been incinerated as municipal solid waste. An effective utilization process for cellulose has been expected to be developed as one of the post-petrochemical methods. Cellulose is a $\beta$ - $(1,4)$-linked homopolymer of many anhydroglucose residues and can be hydrolyzed to glucose using acid catalysts and enzymes. Sasaki et al. ${ }^{39}$ investigated the selective hydrolysis of microcrystalline cellulose in subcritical and supercritical water with a continuous-flow-type micro-reactor. They found that around the critical point of water the hydrolysis rate jumped to a higher level by more than an order of magnitude becoming faster than the following glucose decomposition rate, and resulting in a high yield of glucose being obtained as a hydrolysis product. $^{40}$

Recently, the hydrolysis of cellulose to glucose was examined by Ichiyanagi et al. ${ }^{41}$ in high-pressure $\mathrm{CO}_{2}$ without a catalyst (Scheme 8).
When the reaction was carried out at $180^{\circ} \mathrm{C}$, the water-soluble components obtained were mainly glucose and 5-hydroxymethylfurfural. At a higher temperature of $250{ }^{\circ} \mathrm{C}$, however, the obtained water-soluble component changed to predominantly levulinic acid.

\section{DEVELOPMENT OF RECYCLING TECHNOLOGIES OF PET AND POLYCARBONATE}

In Japan, PET and polycarbonate (PC) have been produced in quantities of 1050 (2008) and 347 (2008) thousand tons, respectively. World levels of production and waste generated from these plastics are expected to increase considerably over coming years. However, these plastics cannot be depolymerized to low-molecular weight compounds and monomers by direct pyrolysis. Furthermore, the thermal decomposition of wasted PET in an incinerator causes problems through discharging carbonic acids such as terephthalic and benzoic acids. Solving these problems through the circulative utilization of these plastics has become an important subject.

\section{Chemical recycling of PET and its relatives}

In recent years, various ways for chemically recycling PET have been developed to recover suitable substances for chemical industries. Solvolysis processes using water, methanol and glycol have been used to gain terephthalic acid (TA), dimethyl terephthalate, methylhydroxyethyl-terephthalate, bis-hydroxyethyl-terephthalate and ethylene glycol (EG) (Scheme 9). All these products can be used in the production of new PETs. Degradation of PET in supercritical methanol was investigated by Goto et al. ${ }^{42}$ to develop a chemical recycling process, in which PET decomposed to dimethyl terephthalate and EG at $300{ }^{\circ} \mathrm{C}$ and $20 \mathrm{MPa}$. A high-molecular weight PET was converted to oligomer with $M_{\mathrm{w}}=1000$ at $600 \mathrm{~s}$. The highest yields of dimethyl terephthalate and EG were $80 \mathrm{~mol} \%$ at $7200 \mathrm{~s}$ and $60 \mathrm{~mol} \%$ at $3600 \mathrm{~s}$, respectively.

Actually, post-consumer PET bottles were demonstrated to be recyclable into TA and EG, which were then used as feedstocks for the reproduction of PET bottles for beverages. Genta et al. ${ }^{43}$ has been developing a chemical recycling plant that uses supercritical methanol to depolymerize PET within a short time. This process can recover high quality monomers equivalent to those of the original monomers produced from petroleum. A feasibility study showed that this recycling process was economically viable.

Chemical recycling of PET without any chemical reagents has been examined by using only high-pressure steam (HPS). Noritake et al. ${ }^{44}$ studied HPS treatment of PET at $1.6 \mathrm{MPa}$ and $200{ }^{\circ} \mathrm{C}$ to obtain fine PET particles without crushing or using acidic/basic catalysts and solvents. When PET was completely decomposed, the maximum yields 


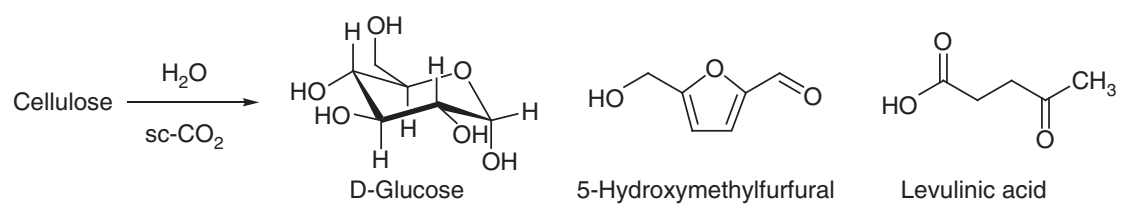

Scheme 8 Effective hydrolysis of cellulose in supercritical $\mathrm{CO}_{2}$.

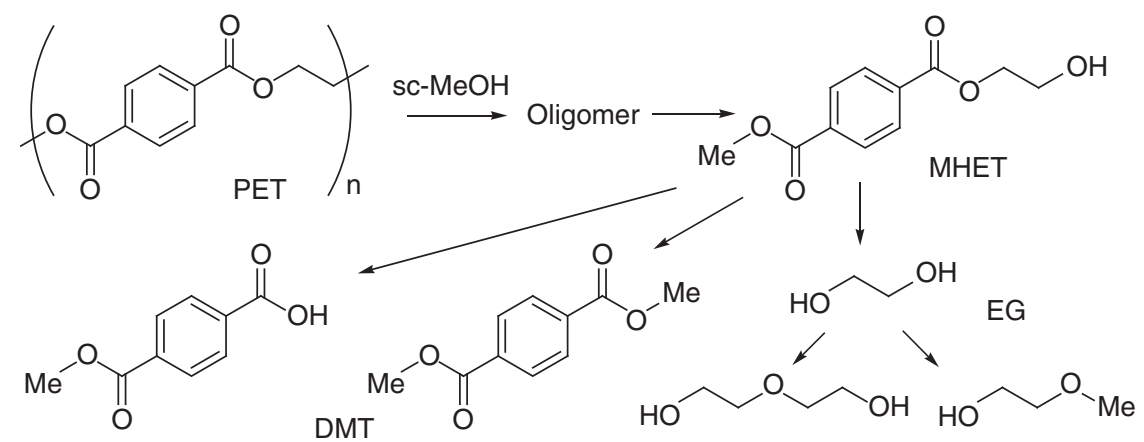

Scheme 9 Chemical recycling of polyethylene terephthalate (PET) in supercritical MeOH. DMT, dimethyl terephthalate; MHET, methylhydroxyethylterephthalate.

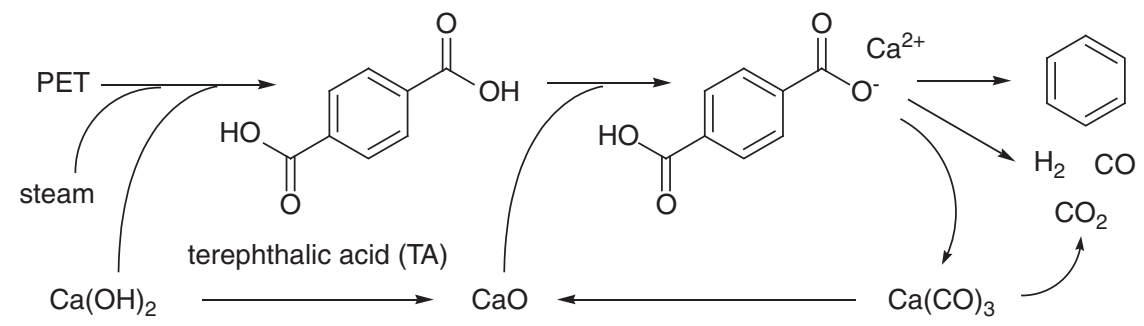

Scheme 10 Chemical recycling of polyethylene terephthalate (PET) with steam and Ca catalysts.

of TA and EG were 67 and 31\%, respectively. Kinetic parameters of the neutral hydrolytic depolymerization of PET using HPS were studied by Zope et al. ${ }^{45}$ using a 0.5 -L high-pressure autoclave in temperature and pressure ranges of $100-250^{\circ} \mathrm{C}$ and $15-451$ p.s.i., respectively. Depolymerization of PET was found to be a first order reaction with the velocity constant of the order of $10^{-2} \mathrm{~min}^{-1}$, and activation energy and frequency factor of $99.58 \mathrm{~kJ} \mathrm{~mole}^{-1}$ and $2.9 \times 10^{8} \mathrm{~min}^{-1}$, respectively.

Hydrolysis of PET into TA and EG with normal pressure steam was conducted in a temperature range of $400-500{ }^{\circ} \mathrm{C}$ by Grause et al.$^{46}$ The highest yield of TA $(72 \%)$ was found at $450{ }^{\circ} \mathrm{C}$ with a residence time of $3-10$ s. The yield of EG was $<10 \%$ in all experiments with most EGs being converted into carbon oxides and hydrogen under these conditions.

Another form of liquefaction process for the recycling of PET that gives valuable raw chemicals, such as benzene, acetophenone and phenol, has also been developed by Yoshioka et al. ${ }^{47}$ They found catalytic effects of metal oxides and hydroxides such as $\mathrm{Ca}(\mathrm{OH})_{2}$ on the pyrolysis of PET. During the pyrolysis at $700{ }^{\circ} \mathrm{C}$ for $30 \mathrm{~min}$, $\mathrm{Ca}(\mathrm{OH})_{2}$ led PET to TA by hydrolysis and to benzene by a following decarboxylation in a high yield of $77 \mathrm{~mol} \%$ of terephthalate units in PET (Scheme 10). In a similar manner, from the pyrolysis of poly(butylene terephthalate) in the presence of $\mathrm{Ca}(\mathrm{OH})_{2}$, the highest yield of benzene $(67 \%)$ was obtained at $700{ }^{\circ} \mathrm{C}$. For poly (ethylene naphthalene-2,6-dicarboxylate) (PEN), a naphthalene yield $(80 \%)$ was achieved at $600{ }^{\circ} \mathrm{C}$ along with a molar ratio of $\mathrm{Ca}(\mathrm{OH})_{2} /$ $\mathrm{PEN}=5 .{ }^{48}$

\section{Chemical recycling of $\mathrm{PC}$}

The chemical recycling of waste bisphenol A (BPA)-type PC has been investigated by various methods including thermal pyrolysis, phenolysis, alcoholysis and hydrolysis. Common chemical recycling methods to recover pure monomer BPA are methanolysis and hydrolysis catalyzed by acids or bases. However, because of the insolubility of PC in water or methanol, the depolymerization of PC requires severe conditions such as long reaction times, high temperature and pressure, or even supercritical conditions.

Alkali-catalyzed methanolysis and hydrolysis of PC in a good solvent such as $\mathrm{N}$-methyl-2-pyrrolidone, 1,4-dioxane and tetrahydrofuran were examined under moderate conditions by Liu et al. ${ }^{49}$ Reaction conditions were optimized for the purpose of recycling into BPA and dimethyl carbonate. Under the optimized conditions at $40{ }^{\circ} \mathrm{C}$ for $35 \mathrm{~min}$ in tetrahydrofuran, the methanolysis conversion of PC was almost $100 \%$ and the yield of BPA was over $95 \%$.

The depolymerization of $\mathrm{PC}$ in supercritical ethanol was carried out in a temperature range of $110-290^{\circ} \mathrm{C}$ by Jie et al..$^{50}$ On the basis of qualitative and quantitative analyses of products, it was found that the random scission and the ester exchange reactions occurred simulta- 


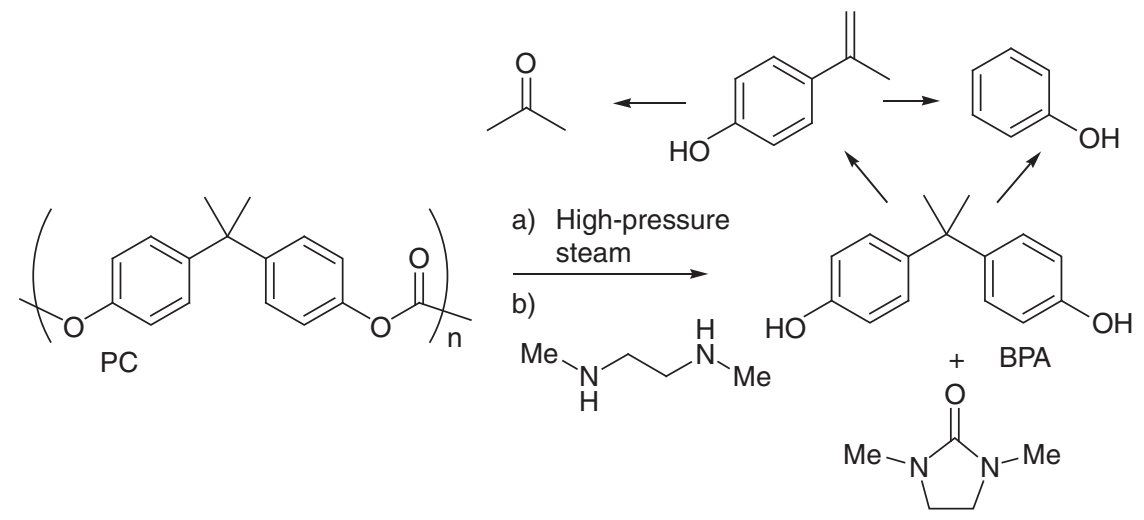

Scheme 11 Chemical recycling of polycarbonate (PC) with (a) high-pressure steam and (b) N,N'-dimethyl-1,2-diamino ethane. BPA, bisphenol A.

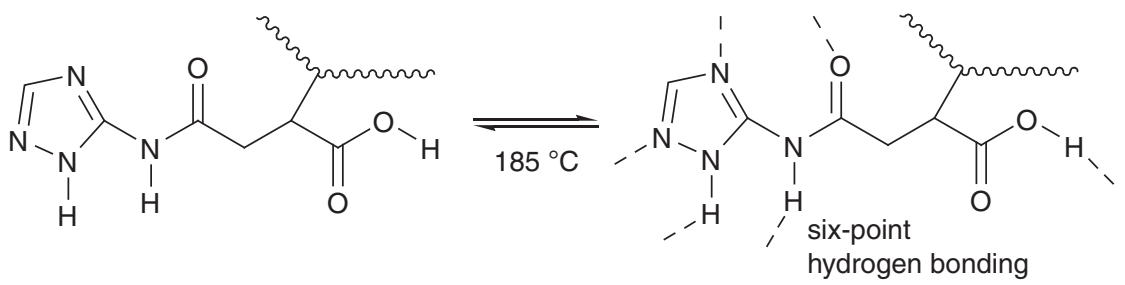

Scheme 12 Thermoreversible hydrogen-bonding network.

neously during the process of ethanolysis. In the supercritical region, in contrast to the reaction in the subcritical region, the molecular weight of PC decreased quickly and degraded completely within $30 \mathrm{~min}$ at $290^{\circ} \mathrm{C}$ into diethyl carbonate and BPA giving yields of 89 and $90 \%$, respectively. On the basis of continuous-distribution kinetics, the mechanism of degradation and the activation energy in the supercritical region were estimated as a random scission and $97.2 \mathrm{~kJ} \mathrm{~mol}^{-1}$, respectively.

Watanabe et al. have applied a HPS treatment for recycling waste PC (Scheme 11a). The PC was completely decomposed into BPA in steam at $300{ }^{\circ} \mathrm{C}$ within 5 min. ${ }^{51}$ The maximum yield of BPA was about $80 \mathrm{~mol} \%$ based on the starting PC, whereas the decomposition in liquid water at $300{ }^{\circ} \mathrm{C}$ gave about a $50 \%$ yield even after $30 \mathrm{~min}$ treatment. The high yield of BPA in HPS was due to the high stability of BPA in HPS compared with when in the liquid water phase, in which the further reaction of BPA progressed in acidic conditions, because $\mathrm{CO}_{2}$ and BPA were dissociated to form ionic species.

Solvolytic recycling of PC to monomer was reported by Oku and co-workers. Hata et al. ${ }^{52}$ investigated the solvolytic recycling of PC with $N, N^{\prime}$-dimethyl-1,2-diaminoethane into BPA and 1,3-dimethylimidazolidin-2-one (Scheme 11b). This method proceeded with a very high conversion of almost $100 \mathrm{wt} \%$ at temperatures lower than $100^{\circ} \mathrm{C}$ for $30 \mathrm{~min}$.

\section{DEVELOPMENT OF REVERSIBLE CROSSLINKING- DECROSSLINKING POLYMER SYSTEMS}

The recycling of thermosetting resins is a very important subject. For example, FRP has been widely used as a high performance material because of its heat-resistance, anti-corrosion properties and mechanical strength. In particular, glass fiber-containing FRP and carbon fiber-containing FRP are extremely high performance composite materials. It is known that FRP is one of the most difficult materials to fractionate into its elemental components because of its mechanical,
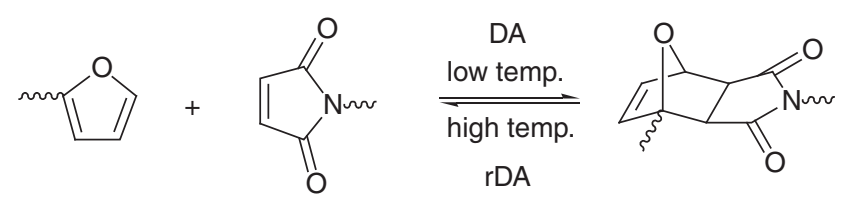

Scheme 13 Forward Diels-Alder (DA) and retro Diels-Alder (rDA) reactions.

chemical and thermal toughness. Recently, however, various novel and functional crosslinked polymers, which have a reversible crosslinkingdecrosslinking function, have been designed and prepared.

\section{Thermoreversible crosslinking-decrosslinking polymers}

Polymer structures with thermoreversible linkages allow the design of recyclable and/or self-healing architectures. Chino et al..$^{53}$ developed thermoreversible crosslinking elastomers by using supramolecular hydrogen-bonding networks (Scheme 12). The networks are based on the six-point hydrogen-bonding structures formed by amide triazole-carboxylic acid moieties. The elastomers obtained showed similar mechanical properties to vulcanized rubbers.

The thermoreversible Diels-Alder (DA) reaction (Scheme 13) has been used in numerous studies, ${ }^{54}$ including polymer synthesis, surface modifications, organic-inorganic polymer hybrids, reversible crosslinking polymer chains/gels ${ }^{55}$ and self-healing polymers. ${ }^{56-58}$ The cycloaddition of furan and maleimide groups (forward DA reaction) proceeds at temperatures lower than ca $100^{\circ} \mathrm{C}$, whereas the retro DA reaction for the depolymerization becomes dominant at higher temperatures. The equilibrium control between the forward DA and retro DA reactions is workable in both solution and bulk state.

Ishida and Yoshie ${ }^{59-61}$ extended furyl-telechelic poly(butylene succinate) prepolymers with bis- and tris-maleimide linkers by the forward DA reaction in a bulk state at $25-80^{\circ} \mathrm{C}$ to produce linear 
and network polymers, respectively. The cycle of forward DA and retro DA reactions was repeatable with no prepolymer deterioration. Furyltelechelic poly(1,4-butylene succinate-co-1,3-propylene succinate) prepolymer was polymerized with tris-maleimide linker by the forward DA reaction in the bulk state above and below the melting temperature of prepolymer to obtain networked polymers. The control of the mechanical properties of polymers was achieved by combining the two dynamic processes of melt-recrystallization and depolymerization-repolymerization, so as to freely convert the networked polymers back and forth between hard and soft materials.

Inoue et al. ${ }^{62}$ prepared intelligent shape-memory polymers through the synthesis of PLA macromonomers with furanyl groups and the crosslinking with linkers having maleimidyl groups. The thermoreversible covalent bonds formed by the forward DA reaction made the polymers recyclable, and the easy transformation in the shapememory programming process was caused by the low crystallinity of the PLA moiety.

Norbornene-copolymers, which have unique properties such as transparency, gas barrier property, low density and chemical resistance, were synthesized from ethylene and 2-norbornene by Donner et al. (Scheme 14). The monomer norbornene was formed by the forward DA addition of ethylene and cyclopentadiene. The norbornene-copolymers were pyrolyzed in a fluidized-bed reactor to give valuable gases (44 wt\%) and aromatic light oils (45 wt\%). The explained mechanism for the pyrolytic degradation was that the expected product, 2-norbornene, was not stable and therefore reproduced ethylene and cyclopentadiene as result of a following retro DA reaction. ${ }^{63}$

\section{Chemo-thermoreversible crosslinking-decrosslinking polymers}

Endo et al. ${ }^{64,65}$ synthesized copolymers having bicycle- and spiroorthoester moieties as pendant groups, which were reversibly changed between the network (ring-opening polymerization) and linear structures (ring-closing depolymerization) in the presence of cationic catalysts (Scheme 15). Crosslinking was enhanced with increases in



Scheme 14 Reversible reactions of norbornene copolymer. DA, Diels-Alder; rDA, retro Diels-Alder. the concentration of the polymer, whereas recovery of the starting linear polymer through decrosslinking increased with decreasing concentration of the crosslinked polymer.

Ruckenstein and Chen ${ }^{66,67}$ used the quaternization and dequaternization behavior of tertiary amine compounds to obtain thermally reversible ionene networks from aqueous colloidal polymer dispersions (Scheme 16). Chlorine-functionalized and amino-functionalized polymers were reacted with ditertiaryamine and dihalide crosslinkers, respectively, to obtain crosslinked polymers. Obtained quaternized crosslinking polymers were reversibly dequaternized on heating at $200{ }^{\circ} \mathrm{C}$ and requaternized again on cooling.

Kojima et al. ${ }^{68-70}$ decrosslinked a sulfur-cured natural rubber by using diphenyl disulfide in supercritical $\mathrm{CO}_{2}$ (Scheme 17). The diphenyl disulfide as the devulcanizing reagent fractionated the vulcanized rubber into a sol component having high molecular weight. The decrease in tensile strength of recycled rubber made from virgin rubber and the devulcanized rubber was only around $10 \%$ at up to 40 p.h.r. of the devulcanized rubber content.

Hashimoto et al. ${ }^{71,72}$ developed chemically recyclable PU elastomers containing acid-sensitive acetal linkages in main and side chains (Scheme 18). Synthesized PU elastomers showed very similar mechanical and thermal properties to those of corresponding PU elastomers. The acid treatment of the elastomers at room temperature caused the hydrolysis of their acetal linkages to regenerate original components.

Otsuka et al. ${ }^{73,74}$ demonstrated a thermodynamic covalent crosslinking-decrosslinking system utilizing alkoxyamine units (Scheme 19). By heating the poly(methacrylic ester)s having alkoxyamine unit side chains, the crosslinking reaction was achieved under stoichiometric control as a result of radical exchange reactions of alkoxyamine moieties. The decrosslinking reaction was achieved by heating in the presence of an excess amount of alkoxyamine.

Kaneszawa et al. ${ }^{75}$ prepared linear and branched aromatic polyamides having cyclic phenylazomethine structures by the direct polycondensation of di- or triamine monomers and dicarboxylic

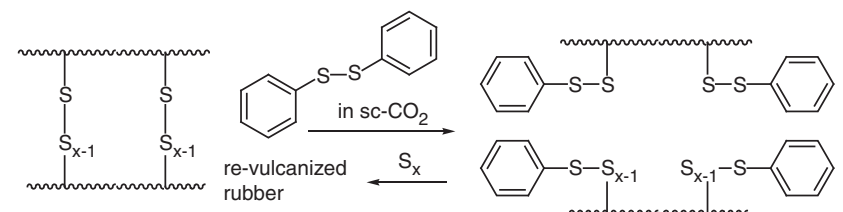

Scheme 17 Reversible crosslinking-decrosslinking by vulcanization and devulcanization.
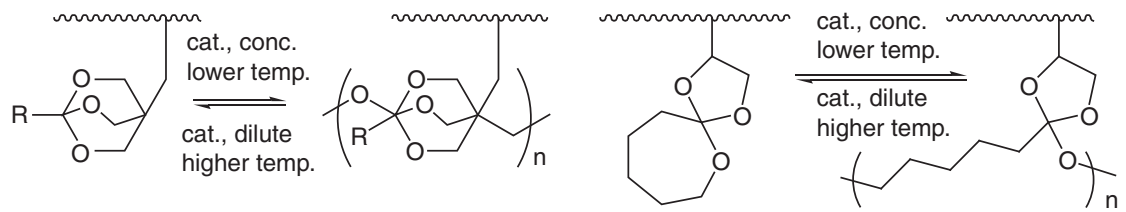

Scheme 15 Reversible ring-opening and -closing reactions of bicycle- and spiro-orthoester moieties.
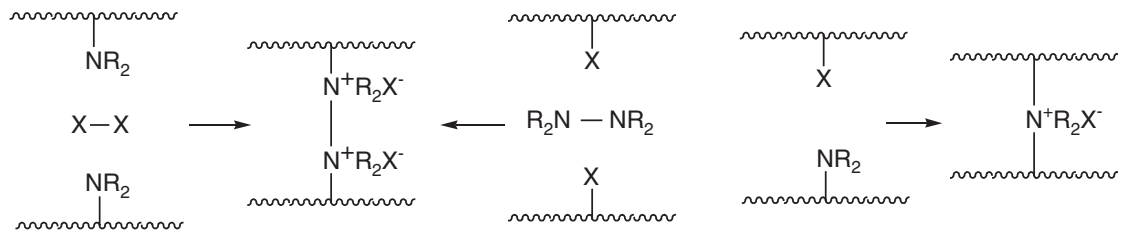

Scheme 16 Reversible crosslinking-decrosslinking by quaternization and dequaternization. 
acids (Scheme 20). The polyamides had a high thermal stability and showed a $10 \%$ weight loss at around $500{ }^{\circ} \mathrm{C}$. On the other hand, the hydrolytic decomposition of azomethine bonds in the presence of dilute sulfuric acid proceeded selectively to reproduce amino and keto-groups. More than $99 \%$ of azomethine bonds were hydrated in $<10$ min at ambient temperature.

Mee et al. ${ }^{76}$ reported thermoreversible covalent crosslinking of maleated ethylene/propylene copolymers with diols (Scheme 21). Covalent hemi-ester crosslinks were formed via the reaction of anhydride side chains and diol linkers. High conversions to hemi-esters were obtained at low temperatures in the presence of acid catalysts. The crosslinked materials were reprocessable at temperatures above $175^{\circ} \mathrm{C}$.

Chaudhary et al. ${ }^{77}$ suggested a thermoreversible crosslinkingdecrosslinking reaction of $\mathrm{PE}$ with urethane derivatives of 2,2,6,6tetramethyl-piperidinyloxy (Scheme 22). The urethane 2,2,6,6-tetramethyl-piperidinyloxy adducts were grafted to PE using a free-radical reaction. On a thermal degradation of a model urethane adduct, an endothermic urethane reversion occurred with the production of diisocyanates at temperatures $>170{ }^{\circ} \mathrm{C}$, but no accompanying exothermic urethane decomposition.

\section{Photo-irradiation participating crosslinking-decrosslinking} polymers

Nagata et al. ${ }^{78}$ prepared a functional poly( $\varepsilon$-caprolactone) with a pendent coumarin group and demonstrated its rapid reversible crosslinking-decrosslinking property using dimerization-dissociation

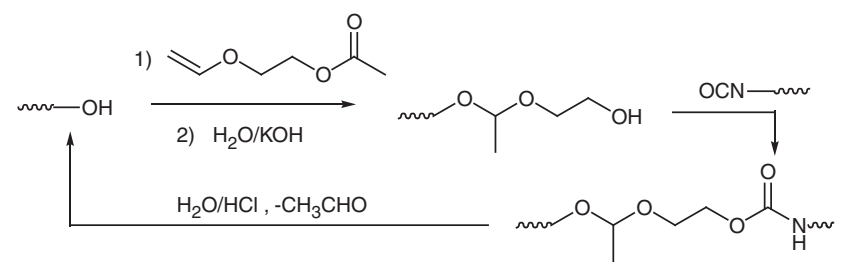

Scheme 18 Reversible crosslinking-decrosslinking by reactions of acidsensitive acetal linkage.
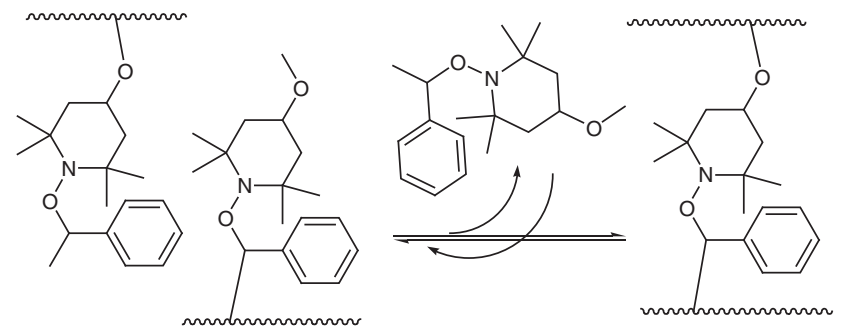

Scheme 19 Reversible crosslinking-decrosslinking by radical exchange reactions of alkoxyamine. reactions under UV irradiations with alternating wavelengths ( $>280$ / $254 \mathrm{~nm}$ ) without photoinitiators (Scheme 23). The crosslinked poly ( $\varepsilon$-caprolactone) films exhibited excellent shape-memory properties after deformation by recovering their permanent shapes instantaneously.

Shirai and co-workers ${ }^{79-81}$ have developed re-workable UV curing materials. Three types of UV curing systems, in which the component materials became soluble in solvents after photo/thermal degradation, were designed and prepared. (i) A base polymer/crosslinker blended system in which multifunctional epoxy compounds as crosslinkers containing tertiary esters of carboxylic acid or sulfonate ester units were synthesized and used in combination with polyvinylphenol (Scheme 24). (ii) A functionalized polymer system bearing epoxy units and alkyl sulfonate groups as thermally degradable linkages in side chains. And, (iii) a system consisting of multifunctional methacrylate or acrylate monomers bearing acetal linkages in molecules. These materials formed networks under UV irradiation, which were then dissolved away under photo-irradiation/thermal treatment.

Johnson et al. ${ }^{82}$ synthesized photo-decrosslinkable network polymers having well-defined segment structures by atom transfer radical polymerization and copper-catalyzed azide-alkyne cycloaddition. Linear azido-telechelic macromonomers possessing a photo-cleavable functionality were crosslinked with a tetrafunctional alkyne by a copper-catalyzed azide-alkyne cycloaddition reaction to form insoluble materials (Scheme 25). The crosslinked polymers were degraded on exposure to UV light of $350 \mathrm{~nm}$ to yield soluble star polymer products of defined molecular weight.

Iwamura et al. ${ }^{83}$ prepared copolymers of a monomer having a 2,4, 5-triphenylimidazole moiety with methyl methacrylate by free-radical polymerization. The crosslinking reaction of the copolymer proceeded with $\mathrm{K}_{3}\left[\mathrm{Fe}(\mathrm{CN})_{6}\right]$ and $\mathrm{KOH}$ at $5-10{ }^{\circ} \mathrm{C}$ (Scheme 26). The obtained crosslinked polymer, which formed hexaarylbiimidazole linkages, was decrosslinked by visible light irradiation or by pressuring with an agate mortar and pestle.

\section{DEVELOPMENTS OF BIOMASS-BASED RECYCLABLE POLYMERS}

So far, various biomass-based polymers have been developed, for example, cellulose acetate, poly(alkylene succinate)s, starch-based blends, poly(3-hydroxy alkanoate)s, PLA and so on. Nowadays, some typical commodity plastics have also been synthesized from

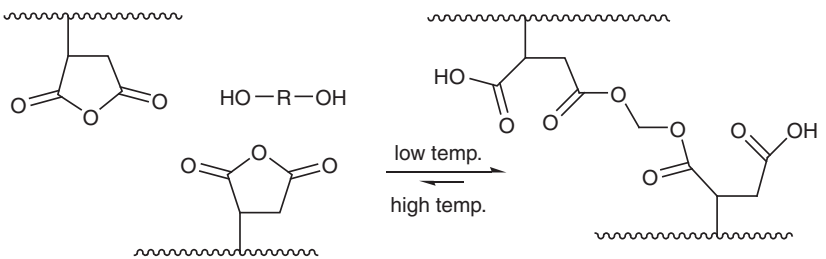

Scheme 21 Reversible crosslinking-decrosslinking of hemi-ester linkage.

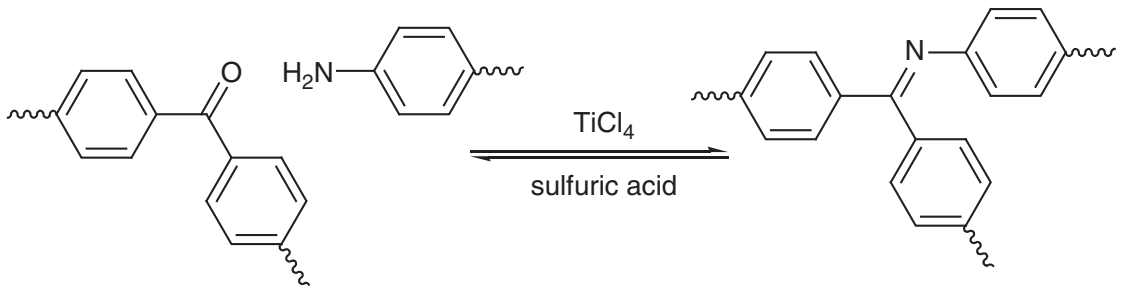

Scheme 20 Reversible condensation and hydrolysis of azomethine linkage. 
biomass. For example, PE, PP, PMMA ${ }^{84}$ polyamide $-4^{85}$ and PC. ${ }^{86}$ If plastic materials are synthesized from renewable resources and circularly utilized with precise control of their depolymerization, an ideal recycling system could be constructed for plastic products, in which the resources and production energy could be minimized. Thus, the development of biomass-based recyclable polymers is significant. In Scheme 27, typical biomass-based recyclable polymers poly(L-lactic acid) (PLLA), poly(tetramethyl glycolide) (PTMG), poly(3-hydroxybutyrate) $(\mathrm{PHB})$ and poly $(\beta, \mathrm{L}-\mathrm{malic}$ acid $)$ are illustrated.

Although PLLA is synthesized from renewable resources such as starch, ${ }^{87}$ the production up to the polymeric form requires much

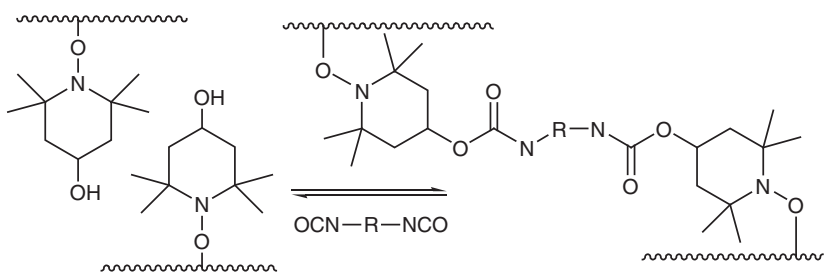

Scheme 22 Reversible crosslinking-decrosslinking of urethane linkage.

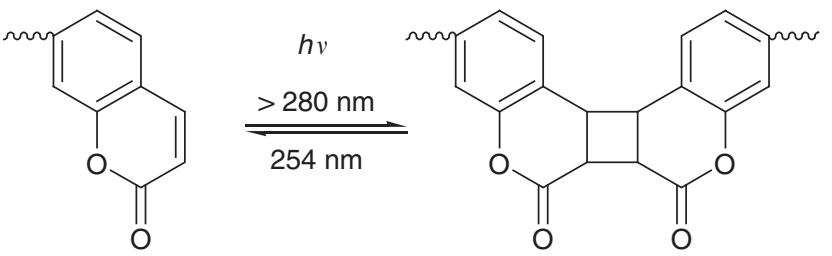

Scheme 23 Reversible dimerization-dissociation reactions of coumarin group under ultraviolet irradiations.

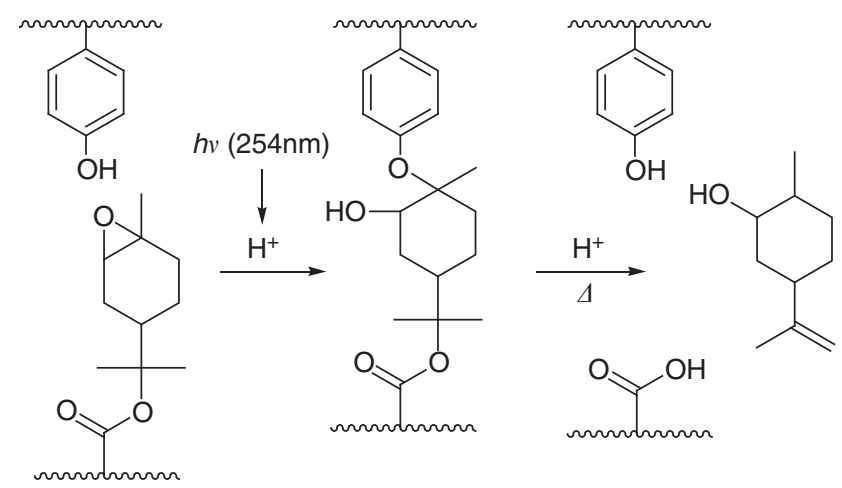

Scheme 24 Re-workable ultraviolet curing-thermodegrading material. energy and many steps (Figure 2): that is, fermentation and purification of lactic acid, condensation for oligomerization, thermal degradation into lactide and polymerization. ${ }^{88}$ If a highly selective depolymerization of PLLA to the cyclic monomer, lactide, can be achieved with high efficiency, it will then be possible to reproduce PLLA via the shortest and most energy efficient route.

PLLA is well known as a material that depolymerizes at higher temperatures into cyclic dimer lactides (Scheme 27). However, the mechanism of thermal degradation of PLLA is complex. Much effort has been expended in clarifying the multiple ways of degradation to control it and recover the valuable products selectively. As a result of these efforts, some important factors on the PLLA degradation, such as polymerization catalyst residues ${ }^{89}$, chain-end structures, ${ }^{90}$ depolymerization catalysts, ${ }^{91-94}$ stereocomplex,${ }^{95}$ racemization, ${ }^{96}$ photodegradation, ${ }^{97}$ blends with other polymers, ${ }^{98-100}$ and so on, have been clarified. Moreover, the degradation kinetics has been precisely analyzed and highly active and selective depolymerization catalysts have been developed. ${ }^{101}$ This has allowed the controlled depolymerization of optically pure PLLA to obtain L,L-lactide selectively with high optical purity even from blends with other plastics. ${ }^{102}$

Recently, Tsunesizumi et al. ${ }^{103}$ demonstrated a selective chemical recycling process of blends PLLA/PE and PLLA/poly(butylene succinate) to degrade the blends into repolymerizable oligomers using environmentally benign catalysts: clay and enzymes. As a result, the regenerated PLLA had a weight-average molecular weight value of $>100000 \mathrm{~g} \mathrm{~mol}^{-1}$.

To overcome some drawbacks of PLA, the racemization-free and depolymerization-controllable PTMG was synthesized from renewable resources: D/L-lactic acids and pyruvic acid (Scheme 27). ${ }^{104,105}$ In addition, biotechnological routes to 2-hyrolxyisobutyric acid,

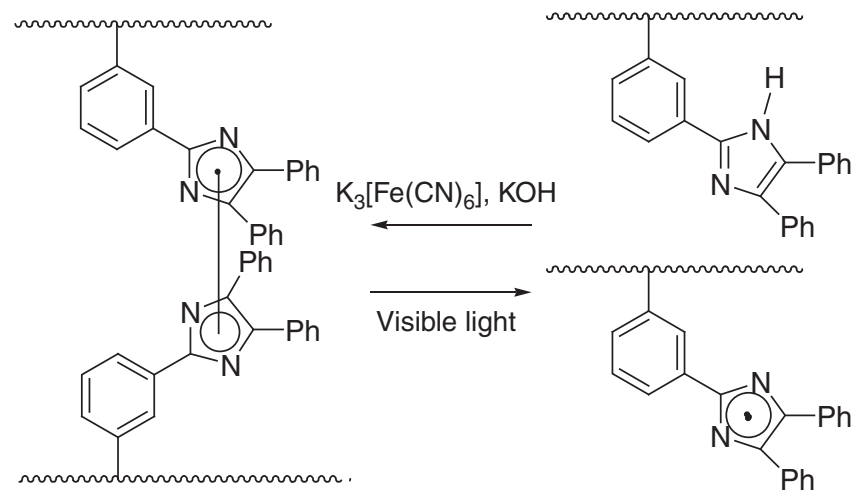

Scheme 26 Reversible crosslinking-decrosslinking of polymer having hexaarylbiimidazole linkage.<smiles>C#CCNC(=O)c1cccc(COC(=O)C(C)C)c1[N+](=O)[O-]</smiles>

Scheme 25 Crosslinking by azide-alkyne cycloaddition and photodegradation. 




Scheme 27 Developments of biomass-based recyclable polymers. PLLA, poly(L-lactic acid); PTMG, poly(tetramethyl glycolide).



Figure 2 Production process of poly(L-lactic acid) (PLLA) from biomass.

which is the acyclic monomer of PTMG, have been proposed. ${ }^{106}$ PTMG overcomes some undesirable properties of PLLA such as low heat-resistance and racemization, which cause a decrease in crystallinity. PTMG was found to be a material having a higher melting point than $200{ }^{\circ} \mathrm{C}$ and a superior recyclability capable of being depolymerized controllably into cyclic dimer tetramethyl glycolide or methacrylic acid by using specific catalysts (Scheme 27). PTMG can be reversibly synthesized from the depolymerized tetramethyl glycolide. Moreover, biomass-based PMMA was prepared by polymerization of methacrylic acid recovered from PTMG waste.

PHB is a well-known microbial and biodegradable polymer, which is accumulated and stored by prokaryotic microorganisms in their cells at levels up to $90 \%$ of their cellular dry weight. PHB has been attracting much interest from researchers not only as an environmentally compatible thermoplastic, but also as a polymeric material obtainable from renewable resources such as sugars, fatty acids, plant oil ${ }^{107}$ and even from $\mathrm{H}_{2}, \mathrm{O}_{2}$ and $\mathrm{CO}_{2}{ }^{108}$ PHB has a highmelting temperature of around $180^{\circ} \mathrm{C}$ and has recently been demonstrated to be a chemically recyclable material with valuable end products such as crotonic acid, linear oligomers having a crotonate end group ${ }^{109}$, and a cyclic trimer ${ }^{110}$ (Scheme 27).

The thermal degradation of PHB was investigated by various kinetic analysis methods in detail to clarify its complex degradation behavior. This resulted in findings of mixed mechanisms comprising a thermal random degradation with subsequent auto-accelerated trans-esterification and a kinetically favored chain reaction from crotonate chain ends, and so on. ${ }^{111,112}$ The chain reaction was kinetically analyzed as a 0th-order weight loss process, which was assumed to be an unzipping $\beta$-elimination reaction, occurring repeatedly at an ester group neighboring the crotonate end group.

The completely selective transformation of PHB into trans-crotonic acid was achieved by thermal degradation using alkali earth metal catalysts. ${ }^{113}$ For example, $\mathrm{Mg}(\mathrm{OH})_{2}$ as a suitable degradation catalyst showed nearly complete selectivity $(\sim 100 \%)$ to trans-crotonic acid. It was suggested that the $\mathrm{Mg}$ catalysts promote the $\beta$-elimination reactions, resulting in a lowering in the degradation temperature and the completely selective transformation. The recovered transcrotonic acid is used for various applications including use as a comonomer in cosmetics.

Portilla-Arias et al. ${ }^{114}$ reported that poly $(\beta, \mathrm{L}-\mathrm{malic}$ acid $)$ was depolymerized above $200^{\circ} \mathrm{C}$ by an unzipping mechanism from chain ends with the generation of fumaric acid, which was secondary 
converted into maleic acid and anhydride (Scheme 27). These aliphatic acids and anhydride are reused to be incorporated in many chemical products.

\section{CONCLUSIONS}

Nowadays, the need to move to a sustainable society and comply with recycling legislation is inducing many innovations toward sustainable development in the scientific field. In the field of polymeric materials, novel recyclable materials and technologies have been and are being developed. Previously, the science and technology of depolymerization and decrosslinking were outside mainstream industrial processes, however with the need to reduce $\mathrm{CO}_{2}$ emissions they are now moving center stage.

Commodity plastics and main engineering plastics are now required to be recycled in compliance with the basic law for establishing a recycling-based society in Japan. In reality, mechanical recycling and energy recovery are still the main ways for achieving recycling. However, as reported, novel technologies for recycling are starting to shift practice to more effective and circulative uses of plastics in a trend that will gain momentum in the near future.

Recently, many biomass-based materials are being developed one after another. In particular, recyclable biomass-based polymers are of great interest and important materials from both a scientific and an environmental point of view, because biomass-based materials have the specific property of being 'carbon neutral', which is an advantage that commodity plastics do not possess. Moreover, some biomassbased materials have been synthesized with good mechanical properties that are in no way inferior and may ultimately surpass those of commodity plastics.

If this trend continues, as appears likely, then, in the near future the circulative use of polymers will become standard practice in the field of plastic products.

\section{ACKNOWLEDGEMENTS}

I am grateful to Professor Takeshi Endo (Kinki University) and Yoshihito Shirai (Kyushu Institute of Technology) for their kind guidance on my researches cited in this article. I also acknowledge Professor Takashi Sawaguchi at Nihon University for his helpful support for preparation of this article.

1 Research Group on Green Chemistry (ed.) Chemistry and Technology for Feedstock Recycling of Plastics (The Society of Polymer Science, Japan, 2010).

2 Mita, I. Effect of structure on degradation and stability of polymers. in Aspect of Degradation and Stabilization of Polymers (ed. Jellinek, H. H. G.) Ch. 6, 247-294 (Elsevier, Amsterdam, 1978).

3 Leonard, J. Heats and entropies of polymerization, ceiling temperatures, equilibrium monomer concentrations, and polymerizability of heterocyclic compounds. in Polymer Handbook Fourth Edition (eds, Brandrup, J., Immergut, E. H., \& Grulke, E. A.) Ch. II, 363-414 (Wiley Interscience, New York, 1999).

4 Zassa, M. D., Favero, M. \& Canu, P. Two-steps selective thermal depolymerization of polyethylene. 1: Feasibility and effect of devolatilization heating policy. J. Anal. Appl. Pyrolysis 87, 248-255 (2010).

5 Westerhout, R. W. J., Kuipers, J. A. M. \& van Swaaij, W. P. M. Recycling of polyethene and polypropene in a novel bench-scale rotating cone reactor by high-temperature pyrolysis. Ind. Eng. Chem. Res. 37, 2293-2300 (1998).

6 Tsuji, T., Tanaka, Y., Shibata, T., Uemaki, O. \& Itoh, H. Two-stage thermal gasification of polyethylene. Nippon Kagaku Kaishi 1999, 759-763 (1999).

7 Kaminsky, W., Schlesselmann, B. \& Simon, C. Olefins from polyolefins and mixed plastics by pyrolysis. J. Anal. Appl. Pyrolysis 32, 19-27 (1995).

8 Scott, D. S., Czernik, S. R., Piskorz, J. \& Radlein, D. S. A. G. Fast pyrolysis of plastic wastes. Energy Fuels 4, 407-411 (1990).

9 Westerhout, R. W. J., Kuipers, J. A. M. \& van Swaaij, W. P. M. Experimental determination of the yield of pyrolysis products of polyethene and polypropene. Influence of reaction conditions. Ind. Eng. Chem. Res. 37, 841-847 (1998).

10 Westerhout, R. W. J., Kuipers, J. A. M. \& van Swaaij, W. P. M. Development of a continuous rotating cone reactor pilot plant for the pyrolysis of polyethene and polypropene. Ind. Eng. Chem. Res. 37, 2316-2322 (1998).
11 Sawaguchi, T., Suzuki, K., Kuroki, T. \& Ikemura, T. Studies on thermal degradation of synthetic polymers. XV. Estimation of the product yield on the basis of intensity function for thermal gasification of isotactic and atactic polypropylenes. J. Appl. Polym. Sci. 26, 1267-1274 (1981).

12 Negelein, D. L., Lin, R. \& White, R. L. Effects of catalyst acidity and HZSM-5 channel volume on polypropylene cracking. J. Appl. Polym. Sci. 67, 341-348 (1998).

13 Sinn, H., Kaminsky, W. \& Janning, J. Processing of plastic waste and scrap tires into chemical raw materials, especially by pyrolysis. Angew. Chem. Int. Ed. Engl. 15, 660-672 (1976).

14 Tsuchiya, K. \& Sakai, T. Extruder type pyrolysis plant for waste plastics. J. S. W. Tech. Rev. 35, 66-74 (1974).

15 Zhang, Z., Hirose, T., Nishio, S., Morioka, Y., Azuma, N., Ueno, A., Ohkita, H. \& Okada, M. Chemical recycling of waste polystyrene into styrene over solid acids and bases. Ind. Eng. Chem. Res. 34, 4514-4519 (1995).

16 Audisio, G. \& Bertini, F. New chemical recycling methodologies: hydrous pyrolysis to recover monomers from polyolefins. Macromol. Symp. 135, 175-182 (1998).

17 Kruse, T. M., Woo, O. S., Wong, H.- W., Khan, S. S. \& Broadbelt, L. J. Mechanistic modeling of polymer degradation: a comprehensive study of polystyrene. Macromolecules 35, 7830-7844 (2002)

18 Sawaguchi, T. \& Seno, M. Controlled thermal degradation of polystyrene leading to selective formation of end-reactive oligomers. J. Polym. Chem. Part A Polym. Chem. 36, 209-213 (1998)

19 Vicente, G., Aguado, J., Serrano, D. P. \& Sánchez, N. HDPE chemical recycling promoted by phenol solvent. J. Anal. Appl. Pyrolysis 85, 366-371 (2009).

20 Uemichi, Y., Takuma, K. \& Ayame, A. Chemical recycling of poly(ethylene) by catalytic degradation into aromatic hydrocarbons using H-Ga-silicate. Chem. Commun. 1998, 1975-1976 (1998)

21 Takuma, K., Uemichi, Y., Sigioka, M. \& Ayame, A. A novel technology for chemical recycling of low-density polyethylene by selective degradation into lower olefins using H-borosilicate as a catalyst. Chem. Lett. 2001, 288-289 (2001).

22 Takuma, K., Uemichi, Y., Sigioka, M. \& Ayame, A. Production of aromatic hydrocarbons by catalytic degradation of polyolefins over H-gallosilicate. Ind. Eng. Chem. Res. 40, 1076-1082 (2001).

23 Uemichi, Y., Seino, A., Nishizaki, T., Kanda, Y. \& Sugioka, M. Degradation of polyethylene into petrochemicals using chlorine tolerant catalyst. Polym. Prepr. Jpn 58, 5377-5378 (2009).

24 Sawaguchi, T., Ikemura, T. \& Seno, M. Preparation of $\alpha, \omega$-diisopropenyloligopropylene by thermal degradation of isotactic polypropylene. Macromolecules 28, 7973-7978 (1995).

25 Sawaguchi, T., Saito, H., Yano, S. \& Seno, M. An effective method for selective formation of telechelic oligomers by controlled thermal degradation of polypropylenes. Polym. Degrad. Stab. 72, 383-391 (2001).

26 Hagiwara, T., Saitoh, H., Tobe, A., Sasaki, D., Yano, S. \& Sawaguchi, T. Functionalization and applications of telechelic oligopropylenes: preparation of R,ö-dihydroxy- and diaminooligopropylenes. Macromolecules 38, 10373-10378 (2005).

27 Sasaki, D. Suzuki, Y, Hagiwara, T., Yano, S. \& Sawaguchi, T. Synthesis and applications of triblock and multiblock copolymers using telechelic oligopropylene. Polymer 49, 4094-4100 (2008).

28 Yoshida, M. Oxidative degradation. in Chemistry and Technologies for Feedstock Recycling of Plastics (ed. Research Group on Green Chemistry) Ch. 2-4, 28-36 (The Society of Polymer Science, Japan, 2010).

29 Shiono, T., Naga, N. \& Soga, K. Synthesis of $\alpha, \omega$-divinylpolyethylene-like polymers from cis-1,4-polybutadiene using partial hydrogenation and metathesis degradation with ethylene. Macromol. Rapid Commun. 14, 323-327 (1993).

30 Shiono, T., Yoshino, O. \& Ikeda, T. Synthesis and oxidative degradation of poly(etheneran-1,3-butadiene). Macromol. Rapid Commun. 21, 1297-1301 (2000).

31 Ishihara, T. \& Shiono, T. Synthesis of poly(propylene-ran-1,3-butadiene) and its metathesis degradation with ethylene. Macromolecules 36, 9675-9677 (2003).

32 Lucas, F., Peruch, F., Carlotti, S., Deffieux, A., Leblanc, A. \& Boisson, C. Synthesis of dihydroxy poly(ethylene-co-butadiene) via metathetical depolymerization: kinetic and mechanistic aspects. Polymer 49, 4935-4941 (2008).

33 Goto, M. Chemical recycling of plastics using sub- and supercritical fluids. J. Supercrit. Fluids 47, 500-507 (2009).

34 Nakagawa, T., Hirota, S., Shibata, K., Yabunouchi, N., Yasuda, Y., Itoh, T., Hidaka, M., Matsui, J., Sato, M., Izumitani, T. \& Imanari, N. Enhanced recycling of FRP using subcritical water (2) (pilot test of styrene-fumaric acid copolymer (SFC) separation and modification process. Polym. Prepr. Jpn 58, 5411-5412 (2009).

35 Suyama, K., Kubota, M., Shirai, M. \& Yoshida, H. Chemical recycling of networked polystyrene derivatives using subcritical water in the presence of an aminoalcohol. Polym. Degrad. Stab. 95, 1588-1592 (2010).

36 Goto, T., Inoue, G., Okajima, I., Sako, T. \& Amano, O. Investigation on energy profit ratio of the recycling of silane cross-linked polyethylene using supercritical alcohol. Hitachi Densen 28, 1-23-1-28 (2009).

37 Yoshida, M., Kobayashi, R., Goto, T. \& Yamazaki, T. Plasticity recovery of crosslinked polyethylene by selective oxidation in supercritical CO2. Polym. Prepr. Jpn 58, 5397-5398 (2009).

38 Matsumoto, T., Motokucho, S., Kojio, K. \& Furukawa, M. Development of hydrolysis method of persistent polyurea using supercritical carbon dioxide in the absence of catalyst. Polym. Prepr. Jpn 58, 5389-5390 (2009).

39 Sasaki, M., Adschiri, T. \& Arai, K. Kinetics of cellulose conversion at $25 \mathrm{MPa}$ in sub- and supercritical water. AIChE J. 50, 192-202 (2004). 
40 Sasaki, M., Kabyemela, B., Malaluan, R., Hirose, S., Takeda, N., Adschiri, T. \& Arai, K. Cellulose hydrolysis in subcritical and supercritical water. J. Supercrit. Fluids 13, 261-268 (1998).

41 Ichiyanagi, H., Furukawa, M., Kojio, K. \& Motokucho, S. Saccharification behavior of microcrystalline cellulose under the high-pressure carbon dioxide including supercritical condition in the absence of catalyst. Polym. Prepr. Jpn 58, 5387-5388 (2009).

42 Goto, M., Koyamoto, H., Kodama, A., Hirose, T., Nagaoka, S. \& McCoy, B. J. Degradation kinetics of polyethylene terephthalate in supercritical methanol. AIChE J. 48, 136-144 (2002).

43 Genta, M., Yano, F., Kondo, Y., Matsubara, W. \& Oomoto, S. Development of chemical recycling process for post-consumer PET bottles by methanolysis in supercritical methanol. Mitsubishi Heavy Industries, Ltd., Technical Review 40, 1-4 (2003).

44 Noritake, A., Hori, M., Shigematsu, M. \& Tanahashi, M. Recycling of polyethylene terephthalate using high-pressure steam treatment. Polym. J. 40, 498-502 (2008).

45 Zope, V. S. \& Mishra, S. Kinetics of neutral hydrolytic depolymerization of PET (polyethylene terephthalate) waste at higher temperature and autogenious pressures. J. Appl. Polym. Sci. 110, 2179-2183 (2008).

46 Grause, G., Kaminsky, W. \& Fahrbach, G. Hydrolysis of poly(ethylene terephthalate) in a fluidised bed reactor. Polym. Degrad. Stab. 85, 571-575 (2004).

47 Yoshioka, T., Handa, T., Grause, G., Lei, Z., Inomata, H. \& Mizoguchi, T. Effects of metal oxides on the pyrolysis of poly(ethylene terephthalate). J. Anal. Appl. Pyrolysis 73, 139-144 (2005)

48 Yoshioka, T., Grause, G., Otani, S. \& Okuwaki, A. Selective production of benzene and naphthalene from poly(butylene terephthalate) and poly(ethylene naphthalene-2,6dicarboxylate) by pyrolysis in the presence of calcium hydroxide. Polym. Degrad. Stab. 91, 1002-1009 (2006).

49 Liu, F.- S., Li, Z., Yu, S.- T., Cui, X., Xie, C.- X. \& Ge, X.- P. Methanolysis and hydrolysis of polycarbonate under moderate conditions. J. Polym. Environ. 17, 208-211 (2009).

50 Jie, H., Ke, H., Qing, Z., Lei, C., Yongqiang, W. \& Zibin, Z. Study on depolymerization of polycarbonate in supercritical ethanol. Polym. Degrad. Stab. 91, 2307-2314 (2006).

51 Watanabe, M., Matsuo, Y., Matsushita, T., Inomata, H., Miyake, T. \& Hironaka, K. Chemical recycling of polycarbonate in high pressure high temperature steam at 573 K. Polym. Degrad. Stab. 94, 2157-2162 (2009).

52 Hata, S., Goto, H., Yamada, E. \& Oku, A. Chemical conversion of poly(carbonate) to 1,3-dimethyl-2-imidazolidinone (DMI) and bisphenol A: a practical approach to the chemical recycling of plastic wastes. Polymer 43, 2109-2116 (2002).

53 Chino, K. \& Ashiura, M. Themoreversible cross-linking rubber using supramolecular hydrogen-bonding networks. Macromolecules 34, 9201-9204 (2001).

54 Aumsuwan, N. \& Urban, M. W. Studies on thermal degradation of synthetic polymers. $\mathrm{XV}$. Estimation of the product yield on the basis of intensity function for thermal gasification of isotactic and atactic polypropylenes. Polymer 50, 33-36 (2009).

55 Peterson, A. M., Jensen, R. E. \& Palmese, G. R. Reversibly cross-linked polymer gels as healing agents for epoxy-amine thermosets. ACS Appl. Mater. Interfaces 1, 992-995 (2009).

56 Kavitha, A. A. \& Singha, N. K. Smart 'All Acrylate' ABA triblock copolymer bearing reactive functionality via atom transfer radical polymerization (ATRP): demonstration of a 'Click Reaction' in thermoreversible property. Macromolecules 43, 3193-3205 (2010).

57 Yoshie, N., Sukarsaatmadja, P. \& Ishida, K. Functionalization of network polymers by using photo-reversible reaction. Polym. Prepr. Jpn 58, 5603-5604 (2009).

58 Deng, G., Tang, C., Li, F., Jiang, H. \& Chen, Y. Covalent cross-linked polymer gels with reversible sol-gel transition and self-healing properties. Macromolecules 43, 1191-1194 (2010).

59 Ishida, K. \& Yoshie, N. Synthesis of readily recyclable biobased plastics by Diels-Alder reaction. Macromol. Biosci. 8, 916-922 (2008).

60 Ishida, K. \& Yoshie, N. Two-way conversion between hard and soft properties of semicrystalline cross-linked polymer. Macromolecules 41, 4753-4757 (2008).

61 Ishida, K., Nishiyama, Y., Michimura, Y., Oya, N. \& Yoshie, N. Hard-soft conversion in network polymers: effect of molecular weight of crystallizable prepolymer. Macromolecules 43, 1011-1015 (2010).

62 Inoue, K., Yamashiro, M. \& Iji, M. Recyclable shape-memory polymer: poly(lactic acid) crosslinked by a thermoreversible Diels-Alder reaction. J. Appl. Polym. Sci. 112, 876-885 (2009)

63 Donner, M. \& Kaminsky, W. Chemical recycling of cycloolefin-copolymers (COC) in a fluidized-bed reactor. J. Anal. Appl. Pyrolysis 74, 238-244 (2005).

64 Endo, T., Suzuki, T., Sanda, F. \& Takata, T. A novel network polymer a linear polymer reversible system. A new cross-linking system consisting of a reversible cross-linkingdepolymerization of a polymer having a spiro orthoester moiety in the side chain. Macromolecules 29, 4819 (1996).

65 Hitomi, M., Sanda, F. \& Endo, T. Reversible crosslinking-decrosslinking of polymers having bicycle orthoester moieties in the side chains. Macromol. Chem. Phys. 200, 1268-1273 (1999)

66 Ruckenstein, E. \& Chen, X. An ambient self-curable latex based on colloidal dispersion in water of two functionalized polymers and the thermally reversible crosslinked films generated. An ambient self-curable latex based on colloidal dispersion in water of two functionalized polymers and the thermally reversible crosslinked films generated. J. Polym. Sci. Part A Polym. Chem. 39, 389-397 (2001).

67 Ruckenstein, E. \& Chen, X. Covalent cross-linking of polymers through ionene formation and their thermal de-cross-linking. Covalent cross-linking of polymers through ionene formation and their thermal de-cross-linking. Macromolecules 33, 8992-9001 (2000)

68 Kojima, M., Tosaka, M. \& Ikeda, Y. Chemical recycling of sulfur-cured natural rubber using supercritical carbon dioxide. Green Chem. 6, 84-89 (2004).

69 Kojima, M., Kohjiya, S. \& Ikeda, Y. Role of supercritical carbon dioxide for selective impregnation of decrosslinking reagent into isoprene rubber vulcanizate. Polymer 46, 2016-2019 (2005)

70 Kojima, M., Tosaka, M., Ikeda, Y. \& Kohjiya, S. Devulcanization of carbon black filled natural rubber using supercritical carbon dioxide. J. Appl. Polym. Sci. 95, 137-143 (2005).

71 Hashimoto, T., Mori, H. \& Urushisaki, M. Poly(tetramethylene ether) glycol containing acetal linkages: New PTMG-based polyol for chemically recyclable polyurethane thermoplastic elastomer. J. Polym. Sci. Part A Polym. Chem. 46, 1893-1901 (2008).

72 Hashimoto, T. Synthesis and chemical recycling of polyurethane materials containing acetal linkages. Kobunshi 57, 350-353 (2008).

73 Higaki, Y., Otsuka, H. \& Takahara, A. A thermodynamic polymer cross-linking system based on radically exchangeable covalent bonds. Macromolecules 39, 2121-2125 (2006).

74 Amamoto, Y., Higaki, Y., Matsuda, Y., Otsuka, H. \& Takahara, A. Programmed thermodynamic formation and structure analysis of star-like nanogels with core cross-linked by thermally exchangeable dynamic covalent bonds. J. Am. Chem. Soc. 129, 13298-13304 (2007).

75 Kanazawa, H., Higuchi, M. \& Yamamoto, K. Synthesis and chemical degradation of thermostable polyamide with imine bond for chemical recycling. Macromolecules 39, 138-144 (2006).

76 van der Mee, M. A. J., Goossens, J. G. P. \& van Duin, M. Thermoreversible covalent crosslinking of maleated ethylene/propylene copolymers with diols. J. Polym. Sci. Part A Polym. Chem. 46, 1810-1825 (2008).

77 Chaudhary, B. I., Peterson, T. H., Wasserman, E., Costeux, S., Klier, J. \& Pasztor Jr, A. J. Thermoreversible crosslinking of polyethylene enabled by free radical initiated functionalization with urethane nitroxyls. Polymer 51, 153-163 (2010).

78 Nagata, M. \& Yamamoto, Y. Synthesis and characterization of photocrosslinked poly(E-caprolactone)s showing shape-memory properties. J. Polym. Sci. Part A Polym. Chem. 47, 2422-2433 (2009).

79 Shirai, M., Morishita, S., Okamura, H. \& Tsunooka, M. Photo-cross-linkable polymers with thermally degradable property. Chem. Mater. 14, 334-340 (2002).

80 Shin, Y.- D., Kawaue, A., Okamura, H. \& Shirai, M. Novel thermally degradable diepoxy crosslinkers containing sulfonate ester groups for photo-crosslinking. Polym. Degrad. Stab. 86, 153-158 (2004).

81 Shirai, M. Reworkable UV curing materials. Prog. Org. Coat. 58, 158-165 (2007).

82 Johnson, J. A., Finn, M. G., Koberstein, J. T. \& Turro, N. J. Synthesis of photocleavable linear macromonomers by ATRP and star macromonomers by a tandem ATRPclick reaction: precursors to photodegradable model networks. Macromolecules 40, 3589-3598 (2007).

83 Iwamura, T. \& Sakaguchi, M. A novel de-cross-linking system from cross-linked polymer to linear polymer utilizing pressure or visible light irradiation. Macromolecules 41, 8995-8999 (2008).

84 Nishida, H., Andou, Y., Watanabe, K., Arazoe, Y., Ide, S. \& Shirai, Y. Poly(tetramethyl glycolide) from renewable carbon, a racemization-free and controlled depolymerizable polyester. Macromolecules 44, 12-13 (2011).

85 Kawasaki, N., Nakayama, A., Yamano, N., Takeda, S., Kawata, Y., Yamamoto, N. \& Aiba, S. Synthesis, thermal and mechanical properties and biodegradation of branched polyamide 4. Polymer 46, 9987-9993 (2005).

86 Fuji, M. \& Yamamoto, M. (Mitsubishi Chemical), Method for producing polycarbonate using dihydroxy compound WO/2010/061928 (27 November 2009).

87 Lunt, J. Large-scale production, properties and commercial applications of polylactic acid polymer. Polym. Degrad. Stab. 59, 145-152 (1998).

88 Vink, E. T. H., Rabago, K. R., Glassner, D. A. \& Gruber, P. R. Applications of life cycle assessment to NatureWorksTM polylactide (PLA) production. Polym. Degrad. Stab. 80, 403-419 (2003).

89 Mori, T., Nishida, H., Shirai, Y. \& Endo, T. Effects of chain end structures on pyrolysis of poly(L-lactic acid) containing tin atoms. Polym. Degrad. Stab. 84, 243-251 (2004).

90 Fan, Y., Nishida, H., Shirai, Y. \& Endo, T. Thermal stability of poly (L-lactide): influence of end protection by acetyl group. Polym. Degrad. Stab. 84, 143-149 (2004).

91 Fan, Y., Nishida, H., Shirai, Y. \& Endo, T. Control of racemization for feedstock recycling of PLLA. Green Chem. 5, 575-579 (2003).

92 Fan, Y., Nishida, H., Mori, T., Shirai, Y. \& Endo, T. Thermal degradation of poly (L-lactide): effect of alkali earth metal oxides for selectiveL,L-lactide formation. Polymer 45, 1197-1205 (2004).

93 Nishida, H., Fan, Y., Mori, T., Oyagi, N., Shirai, Y. \& Endo, T. Feedstock recycling of flame-resisting poly(lactic acid)/aluminum hydroxide composite to L,L-lactide. Ind. Eng. Chem. Res. 44, 1433-1437 (2005).

94 Motoyama, T., Tsukegi, T., Shirai, Y., Nishida, H. \& Endo, T. Effects of MgO catalyst on depolymerization of poly-L-lactic acid to L,L-lactide. Polym. Degrad. Stab. 92, 1350-1358 (2007)

95 Fan, Y., Nishida, H., Shirai, Y., Tokiwa, Y. \& Endo, T. Thermal degradation behavior of poly(lactic acid) stereocomplex. Polym. Degrad. Stab. 86, 197-208 (2004).

96 Tsukegi, T., Motoyama, T., Shirai, Y., Nishida, H. \& Endo, T. Racemization behavior of L,L-lactide during heating. Polym. Degrad. Stab. 92, 552-559 (2007). 
97 Yasuda, N., Wang, Y., Tsukegi, T., Shirai, Y. \& Nishida, H. Quantitative evaluation of photodegradation and racemization of poly(L-lactic acid) under UV-C irradiation. Polym. Degrad. Stab. 95, 1238-1243 (2010).

98 Omura, M., Tsukegi, T., Shirai, Y., Nishida, H. \& Endo, T. Thermal degradation behavior of poly(lactic acid) in a blend with polyethylene. Ind. Eng. Chem. Res. 45, 2949-2953 (2006).

99 Omura, M., Tsukegi, T., Shirai, Y. \& Nishida, H. Selective depolymerization of poly-Llactic acid into L,L-lactide from blends with polystyrene. Kobunshi Ronbunshu 64 745-750 (2007)

100 Omura, M., Tsukegi, T., Shirai, Y. \& Nishida, H. Selective depolymerization of poly-L-lactic acid into L,L-lactide from blends with polybutylene succinate related copolymers. Kobunshi Ronbunshu 64, 751-757 (2007).

101 Nishida, H., Tsukegi, T., Ando, Y. \& Shirai, Y. Highly effective monomer recycling of poly(lactic acid) in polymer alloys. Polym. Prepr. Jpn 59, 5284-5285 (2010).

102 Tsukegi, T., Yasuda, N., Hashimoto, N., Yanagida, H., Shirai, Y. \& Nishida, H. Chemical recycling of poly(L-lactic acid) compounds contained with aluminum hydroxide type flame retardant with a twin screw extruder. Seikei-Kakou 22 585-591 (2010).

103 Tsuneizumi, Y., Kuwahara, M., Okamoto, K. \& Matsumura, S. Chemical recycling of poly(lactic acid)-based polymer blends using environmentally benign catalysts. Polym. Degrad. Stab. 95, 1387-1393 (2010)

104 Watanabe, K., Ando, Y., Shirai, Y. \& Nishida, H. Racemization-free monomer: $\alpha$-hydroxy isobutyric acid from bio-based lactic acid. Chem. Lett. 39, 698-699 (2010).
105 Andou, Y., Watanabe, K., Shirai, Y. \& Nishida, H. Physical properties and thermaldegradability of polytetramethyglycolide (PTMG). Polym. Prepr. Jpn 59, 5403-5404 (2010)

106 Rohwerder, T. \& Müller, R. H. Biosynthesis of 2-hydroxyisobutyric acid (2-HIBA) from renewable carbon. Microb. Cell Fact. 9, 13 (2010)

107 Tokiwa, Y. \& Ugwu, C. U. Biotechnological production of (R)-3-hydroxybutyric acid monomer. J. Biotechnol. 132, 264-272 (2007).

108 Ishizaki, A., Tanaka, K. \& Taga, N. Biosynthesis of 2-hydroxyisobutyric acid (2-HIBA) from renewable carbon. Appl. Microbiol. Biotechnol. 57, 6-12 (2001).

109 Abe, H. Thermal degradation of environmentally degradable poly(hydroxyalkanoic acid)s. Macromol. Biosci. 6, 469-486 (2006).

110 Melchiors, M., Keul, H. \& Höcker, H. Depolymerization of poly[(R)-3-hydroxybutyrate] to cyclic oligomers and polymerization of the cyclic trimer: An example of thermodynamic recycling. Macromolecules 29, 6442-6451 (1996).

111 Ariffin, H., Nishida, H., Shirai, Y. \& Hassan, M. A. Determination of multiple thermal degradation mechanisms of poly(3-hydroxybutyrate). Polym. Degrad. Stab. 93, 1433-1439 (2008).

112 Ariffin, H., Nishida, H., Shirai, Y. \& Hassan, M. A. Anhydride production as an additional mechanism of poly(3-hydroxybutyrate) pyrolysis. J. Appl. Polym. Sci. 111, 323-328 (2009).

113 Ariffin, H., Nishida, H., Shirai, Y. \& Hassan, M. A. Highly selective transformation of poly[(R)-3-hydroxybutyric acid] into trans-crotonic acid by catalytic thermal degradation. Polym. Degrad. Stab. 95, 1375-1381 (2010).

114 Portilla-Arias, J. A., Garcỳa-Alvarez, M. de llarduya, A. M., Holler, E. \& Munoz-Guerra, S. Thermal decomposition of fungal poly( $\beta, L-m a l i c$ acid $)$ and poly $(\beta, L-m a l a t e) s$. Biomacromolecules 7, 3283-3290 (2006).

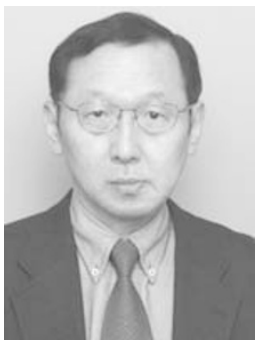

Haruo Nishida received his B. Eng. Degree in 1978 and M. Eng. Degree in 1980 from Kumamoto University under the supervision of Professor Hiroaki Egawa and Professor Takamasa Nonaka. He received his D. Degree in 1995 from Tokyo Institute of Technology under the supervision of Professor Takeshi Endo and Professor Yoshio Inoue. He joined Tokuyama in 1981. He collaborated with Dr Yutaka Tokiwa at Agency of Industrial Science and Technology for 1990-1992. In 2000, he joined Kinki University as an Associate Professor and moved to Kyushu Institute of Technology as a Professor in 2007. He is on the editorial advisory board of Polymer Degradation and Stability. His research interests include polymer chemistry, green chemistry and ecomaterials. 